\title{
An Appraisal of Ozone Layer Depletion and Its Implication on the Human Environment
}

\author{
O.J ADEOYE S. A. AINA
}

\begin{abstract}
Ozone layer depletion is a reality which poses threat to human survival if not curtail. However, it has received international attention and cooperation in which nation states have come up with series of conventions and protocols. It is no more gainsaying that the protection of the environment is a duty of all as no one can be left behind.This paper examines the ozone depletion substance, the impacts and implications of ozone layer depletion on human health and environment, and possible suggestion out of the challenges. The methodology adopted is basically doctrinal with primary sources from various international instruments relating to ozone layer depletions. The secondary sources are mainly from articles in journals, commentaries and online publications.It is our humble conclusion that ozone layer protection is a global and continuous assignment in which all hands must be on deck in order to meet the desirable target. The international communities' cooperation in this regard is commendable.
\end{abstract}

DOI: $10.7176 / \mathrm{JLPG} / 83-02$

Publication date:March $31^{\text {st }} 2019$

\section{INTRODUCTION}

There are many situations where human activities have significant effects on the environment. Ozone layer depletion is one of them. Ozone $\left(\mathrm{O}_{3}\right)$ is a stratospheric layer that plays important role in providing support to humans for their survival. It is an essential factor for many global, biological and environmental phenomena. ${ }^{1}$ This layer absorbs $93-99 \%$ of the sun high frequency ultraviolet light, which is potentially damaging to life on earth. ${ }^{2}$ Ozone layer depletion is the reduction of the protective layer of ozone in the stratosphere by chemical pollution.

One of the main reasons for the widespread concern about depletion of the ozone layer is the anticipated increase in the amounts of ultra violet radiation received at the surface of the earth and its effect on human health and the environment. The objective of this paper is to examine the concept and meaning of ozone layer depletion, causes of ozone layer depletion as well as international community's reaction to ozone layer depletion. The effect of ozone layer depletion on the environment is also examined.

\section{OZONE LAYER DEPLETION}

Far above the ground, a thin layer of ozone absorbs ultraviolet sunlight, thus protecting everything and everyone on the lithosphere from exposure to the deadly radiation. Ozone also is a colourless gas found in the upper atmosphere of the Earth. It is formed when oxygen molecules absorb ultraviolet photons and undergo chemical reaction known as photolysis. ${ }^{3}$

The ozone molecule is composed $\left(\mathrm{O}_{3}\right)$ which is composed of three oxygen atoms. It forms when atmospheric oxygen $\left(\mathrm{O}_{2}\right)$ interacts with solar radiation and breaks apart into two oxygen atoms; each atom then joins up with an oxygen molecule. ${ }^{4}$ The ozone molecule is unstable, so it soon decays to again form molecule oxygen. This cyclic process absorbs radiation and is constantly occurring in the upper reached of the stratosphere. The thickness of the ozone layer is 300 Dobson units approximately 3 millimetres 5

The ozone layer is contained within the stratosphere which is the layer before the mesosphere. It is important to note that ninety percent of the ozone in the atmosphere is located in the stratosphere. According to a learned author,

The nature of ozone depends on the location within the atmosphere. At the ground level where it can interact with plants and animals, it is a pollutant but in the stratosphere, the ozone is a shield for the earth's surface as it protects the earth surface from the direct effect of ultraviolet ray which can cause skin cancer, blindness related to development of cataracts, gene mutations, and income system damage. ${ }^{6}$

In 1974, chemists Mario Molina and Frank Sherwood Rowland of the University of California, Irvine, first warned of the danger of ozone deterioration in the atmosphere when they studied the impacts of CFCs in the

\footnotetext{
${ }^{1}$ Anjali, A, et.al) Depletion of the Ozone Layer and Its Consequences: A Review. American Journal of Plant Science, 2013, 4, 1990- 1997.

${ }^{2}$ Abbritton, Daniel, What should Be Done in a Science Assessment in Protecting the Ozone Layer: Lesson, Models, and Prospect. 1988

$3<\mathrm{https}$ ://www.google.com/search?ei=C2GzW5GWG4HvgAadvJugBQ\&q=cause+ozone+layer+depletion

$4<$ https://sciencing.com/what-ozone-layer-depletion-4601116.html $>$ accessed on $26^{\text {th }}$ September, 2018.

5 ibid

${ }^{66}$ Adebayo, W. A. Contemporary Issues in International Environment Law. Ekiti: Ekiti State University Printing Press. P. 119.
} 
earth's atmosphere. They discovered that CFC molecules were stable enough to remain in the atmosphere until they got into the middle of the stratosphere where they would finally be broken down by ultraviolet radiation releasing a chlorine atom. They thus proposed that these chlorine atoms might be expected to cause the breakdown of the large amount of ozone (O3) in the stratosphere. Their predictions were corroborated by observation in 1985, when an ozone hole was detected above the Antarctic.

Each year since the late 1970s, much of the protective layer of stratospheric ozone above Antarctic has disappeared during September, creating what is popularly known as the ozone hole. This is the emergence of the concept ozone layer depletion which implies that the thickness of the ozone layer is depleting thereby exposing the lithosphere to direct radiation from the ultraviolet sunlight.

\section{CAUSES OF OZONE LAYER DEPLETION}

Ozone depletion is caused by chemicals containing the elements chlorine and bromine, which are halogens. They are important components of a class of refrigerants called chlorofluorocarbons (CFCs) that were in heavy use in the mid $20^{\text {th }}$ century. CFCs are inert and able to migrate to the upper atmosphere on wind currents, where the sun's ultra violet energy breaks them apart.

In the presence of Ultra Violet (UV) light, these gases dissociate, releasing chlorine atoms, which then go on to catalyse ozone destruction. The Cl- catalysed ozone depletion can take place in the gas phase, but it is dramatically enhanced in the presence of polar stratospheric clouds (PSCs). ${ }^{1}$ These substances also known as ozone depleting substances are responsible for depleting the thickness of the ozone layer in the stratosphere thereby allowing the direct reflection of ultra violet radiation from the sunlight.

The following are the major causes of ozone depletion

1. Production and emission of Chlorofluorocarbons (CFCs)

2. Hydrochlorofluorocarbons (HCFCs) and Volatile Organic Compounds (VOCs).

3. Chlorine Monoxide (CIO).

\section{OZONE DEPLETING SUBSTANCES}

Paragraph 4 of the Annex I of the convention provides that:

The following chemicals substances of natural and anthropogenic origin, not listed in order of priority, are thought to have potential to modify the chemicals and physical properties of the ozone layer. ${ }^{2}$

However, the convention leading to the Montreal Protocol has undergone series of amendment leading to additional targeted chemicals as ozone depleting substances (ODS). The substances in Group 1 of Annex A are: ${ }^{3}$
Molecular Formula
Halocarbon Number
Name
(CFC- 11)
2. $\mathrm{CF}_{2} \mathrm{CI}_{2}$
(CFC- 12)
3. $\mathrm{C}_{2} \mathrm{~F}_{3} \mathrm{CI}_{3}$
(CFC- 113)
4. $\mathrm{C}_{2} \mathrm{~F}_{4} \mathrm{CI}_{2}$
(CFC-114)
(CFC- 115)
Trichlorofluoromathane
Dichlorodifluoromenthane
Trichlorotrifluoroethane
Dichlorotetrafluoroethane
Chloropentafluoroethane

1. $\mathrm{CFCI}_{3}$

5. $\mathrm{C} 2 \mathrm{~F} 5 \mathrm{Cl}$

\section{MONTREAL PROTOCOL AND OZONE LAYER}

Through the 1970s and the 1980s, the international community became increasingly concerned that ozone Depleting Substance (ODS) would harm the ozone layer. In 1985, the Vienna Convention for the Protection of the Ozone Layer formalised international cooperation on the issue. This cooperation however resulted in the signing of the Montreal Protocol on Substances that Deplete the Ozone Layer in 1987.

After the Montreal Protocol was signed, new data showed worse- than- expected damage to the ozone layer. In 1992, the parties to the Protocols decided to alter the terms of the 1987 agreement to end the Ozone depleting substances.

The Montreal Protocol on substance that depletes the ozone layer is an international treaty design to protect the ozone layer by phasing out the production of numerous substances that are responsible for ozone depletion. The Protocol is a global agreement to protect the stratospheric ozone layer by phasing out the production and consumption of ozone depleting substances (ODS) by 2030. The stratospheric ozone layer filters out harmful ultraviolet radiation, which is associated with an increased prevalence of skin cancer and cataracts, reduced agricultural productivity and disruption of marine ecosystems.

However, there are few exceptions for essential uses of the ODS. These are cases where no acceptable

\footnotetext{
${ }^{1}$ Parson, Robert, Antarctic Ozone Depletion. http://faqs.org accessed on $28^{\text {th }}$ September, 2018.

${ }^{2}$ Adebayo, W. A. Op.cit P. 121.

${ }^{33}<$ http://www.theozonehole.com/odcs.htm $>$ accessed on $28^{\text {th }}$ September, 2018.
} 
substitutes were found

The Protocol has been amended at eight different times- London in 1990; Nairobi in 1991; Copenhagen in 1992; Bangkok in 1993; Vienna in 1995, Montreal in 1997 and Beijing in 1999 and Kighali in 2016. The 1990 amendments added twelve chemicals to the list of ozone depleting substances and a new list of substances including Hydrobromofluorocarbons (HBFCs) and Methyl bromide (CH3Br) were included for regulations. ${ }^{1}$

The Montreal Protocol is the first treaty to achieve universal ratification by all countries in the world. This success has made it possible through the protocol to place the ozone layer which was in peril on the path of repair. The Montreal Protocol Scientific Assessment Panel estimates that with implementation of the Montreal Protocol, we can expect near complete recovery of the ozone layer by the middle of the $21^{\text {st }}$ century.

\section{KIGHALI AMENDMENT TO THE MONTREAL PROTOCOL}

Parties to Montreal Protocol adopted the Kighali Amendment precisely on $15^{\text {th }}$ October, 2016. The essence of the amendment is to phase down production and consumption of hydrofluorocarbons (HFCs) worldwide. HFCs are widely used as alternatives to Ozone depleting substance (ODS) such as hydrochlorofluorocarbons (HCFCs) and chlorofluorocarbons (CFCs) which is already controlled under the Montreal Protocol.

This amendment creates market certainty and opens international market to new technology that is better for the environment without compromising performance. It calls on all countries to gradually phase down their production and consumption of HFCs in the coming decades using the flexible innovative and effective approaches the Montreal Protocol has used for decades.

\section{EFFECTS OF OZONE LAYER ON THE ENVIRONMENT}

Ozone depletion is affecting the human health and environment negatively, as it allows the penetration of UV radiations to reach the Earth. Ultraviolet radiation which is as a result of ozone layer depletion can be divided into three categories of increasing energy. They are: UV-A, UV-B, and UV-C. UV-A is a low energy form of UV and has only minimal biological effects. UV-B, a high energy form, causes the most damage to living organisms and materials. UV-C is absorbed by the oxygen in the atmosphere and never reaches us.

Ozone layer depletion thus allows ultra violet radiation particularly UV-B to penetrate the earth thereby posing both environmental and health challenges. The various effects of ozone layer depletion will be examined under the following rubrics.

\section{Effects on Air Quality}

Reductions in stratospheric ozone lead to increased penetration of UV-B radiation to the lower atmosphere, and therefore to a general increase in the photochemical reactivity of the troposphere. These changes are believed to affect concentrations of key tropospheric gases such as ozone (the major constituent of urban photochemical smog), peroxides (important contributors to the acidification of rain) and the hydroxyl radical $(\mathrm{OH})$, which is the major oxidant responsible for the atmospheric residence time of species such as carbon monoxide, methane, VOC, nitrogen and sulfur oxides, and other constituents including many substitutes for ozone-depleting substances. However, the magnitude and even the sign of the tropospheric composition responses to increased UV-B levels depend on the chemical environment, especially the local amounts of nitrogen oxides, VOC, and water vapour. $^{2}$

Recent modelling studies confirm and extend earlier work showing that remote regions should experience lower tropospheric O3 levels due to enhanced UV-B radiation, and higher $\mathrm{OH}$ concentrations leading to shortened lifetimes for many atmospheric constituents as well as to higher levels of peroxides. However, the newest study also suggests that such effects will be rather minor in the upper troposphere due to the low levels of water vapour present at those altitudes. Another recently published study illustrates the effect of stratospheric perturbations on tropospheric chemistry by showing increases in tropical tropospheric methane and carbon monoxide for several months following the Mt. Pinatubo eruption, which injected large amounts of UVabsorbing sulphur dioxide into the stratosphere and thus temporarily reduced tropospheric $\mathrm{OH}$ radical production. ${ }^{3}$

\section{Effects on Terrestrial Plant.}

Ultra violet radiation not only affects humans, but wildlife as well. Excessive UVB inhibits the growth processes of almost all green plants. There is concern that ozone depletion may lead to a loss of plant species and reduce global food supply. Any change in the balance of plant species can have serious effects, since all life is interconnected.

\footnotetext{
${ }^{1}$ Adebayo, W. A. Op. cit. P. 124.

${ }^{2} \mathrm{http}$ ://sedac.ciesin.columbia.edu/ozone/UNEP/unep97summary.html accessed on 29th September, 2018.

3 Ibid.
} 
Indirect changes caused by UVB (such as changes in plant form, how nutrients are distributed within the plant timing of developmental phases and secondary metabolism) are also effects of UVB. These effects can have important implications for plant competitive balance, herbs, plant diseases and biogeochemical cycles. ${ }^{1}$

It is a known fact that the physiological and developmental processes of plants are affected by UV-B radiation. Scientists believe that an increase in UV-B levels would necessitate using more UV-B tolerant cultivar and breeding new tolerant ones in agriculture. In forests and grasslands increased UV-B radiation is likely to result in changes in species composition (mutation) thus altering the bio-diversity in different ecosystems. UV-B could also affect the plant community indirectly resulting in changes in plant form, secondary metabolism, etc. These changes can have important implications for plant competitive balance, plant pathogens and biogeochemical cycles.

\section{Effects on Aquatic Ecosystems}

While more than 30 percent of the world's animal protein for human consumption comes from the sea alone, it is feared that increased levels of UV exposure can have adverse impacts on the productivity of aquatic systems. High levels of exposure in tropics and subtropics may affect the distribution of phytoplankton which forms the foundation of aquatic food webs. Scientists have demonstrated a direct radiation in phytoplankton production due to ozone depletion related increases in UVB.

Reportedly a recent study has indicated 6-12 percent reduction in phytoplankton production in the marginal ice zone due to increases in UV-B. UV-B can also cause damage to early development stages of fish, shrimp, crab, amphibians and other animals, the most severe effects being decreased reproductive capacity and impaired larval development. This has a great implication for the whole marine food chain.

\section{Effects on Human and Animal Health}

Increased penetration of solar UV-B radiation is likely to have profound impact on human health with potential risks of eye diseases, skin cancer and infectious diseases [6]. UV radiation is known to damage the cornea and lens of the eye. Chronic exposure to UV-B could lead to cataract of the cortical and posterior subcapsular forms. UV-B radiation can adversely affect the immune system causing a number of infectious diseases. In light skinned human populations, it is likely to develop nonmelanoma skin cancer (NMSC). Experiments on animals show that UV exposure decreases the immune response to skin cancers, infectious agents and other antigens. Effects of ozone layer depletion on human include:

1. Skin cancer: exposure to ultraviolet rays poses an increased risk of developing several types of skin cancers, including malignant melanoma, basal and squamous cell carcinoma.

2. Eye damage: direct exposure to UV radiations can result in photokeratitis (snow blindness) and cataracts.

3. Immune system damage: effects on UV ray include impairment of the immune system. It also weakens the immune system. This will increase the level of diseases since there is no immunity to fight against them.

4. Accelerated aging of skin: constant exposure to UV radiation can cause photo allergy, which result in outbreak of rashes in fair skinned people.

5. Other effects which ozone chemicals can cause difficulty in breathing, chest pain, throat irritation, and hamper lung functioning.

\section{Effects on Climate Change}

Ozone depletion and climate change are linked in a number of ways, but ozone depletion is not a major cause of climate change. Atmospheric ozone has two effects on the temperature balance of the Earth. It absorbs solar ultraviolet radiation, which heats the stratosphere. It also absorbs infrared radiation emitted by the Earth's surface, effectively trapping heat in the troposphere. Therefore, the climate impact of changes in ozone concentrations varies with the altitude at which these ozone changes occur. The major ozone losses that have been observed in the lower stratosphere due to the human-produced chlorine- and bromine-containing gases have a cooling effect on the Earth's surface. ${ }^{2}$

On the other hand, the ozone increases that are estimated to have occurred in the troposphere because of surface- pollution gases have a warming effect on the earth's surface, thereby contributing to the greenhouse effect. $^{3}$

\section{CONCLUSION}

\footnotetext{
${ }^{1} \mathrm{Htpps}: / /$ www.epa.gov/ozonelayer-depletion.

${ }^{2}$ Sivasakthivel, T \& Reddy, K. Ozone Layer Depletion and its Effects: A Review. International Journal of Environmental Science and Development, 2(1), 2011, P. 35

${ }^{3}$ Ibid. P. 36
} 
Under the auspices of United Nations Environment Programme (UNEP), Governments of the world, including the United States have cooperatively taken action to stop ozone depletion with the "The Montreal Protocol on Substances that Deplete the Ozone Layer", signed in 1987. Scientist's are concerned that continued global warming will accelerate ozone destruction and increase stratospheric ozone depletion. Ozone depletion gets worse when the stratosphere (where the ozone layer is), becomes colder.

However, with the cooperation of the international communities in reducing the production and consumption of ozone depletion substances, the ozone layer is recuperating. Continued decline in ODS emission are expected to result in a near complete recovery of the ozone layer near the middle of the $21^{\text {st }}$ century. The long time scale for the recovery is due to the slow rate at which ODS are removed from the atmosphere by natural processes. 